\title{
Twee oevers, één vredespark?
}

ESSAY Dorien Van den Boer

\section{Het innemen of veranderen van plaatsen kan een krachtig instrument zijn voor sociale bewegingen om hun boodschap zichtbaar te maken voor een breed publiek. In het Jordaans-Israëlische grensgebied pro- beert de milieubeweging 'Friends of the Earth Middle East' van deze politiek geladen ruimte een vredespark te realiseren.}

Plaatsen zijn geen louter passieve, blanco pagina's waarop een nieuw verhaal geschreven wordt, ze zijn altijd sociaal geconstrueerd en leiden hun eigen leven. Volgens Doreen Massey kunnen we plaatsen begrijpen in termen van sociale relaties, die voortdurend onder constructie en nooit volledig af zijn. Als we ons plaatsen inbeelden als veranderlijke, open entiteiten, gaat er een wereld van ruimtelijke alternatieven en verscheidenheid open. Toch leren we plaatsen kennen als schijnbaar coherente gehelen. Verschillende betekenisgevende elementen worden samen gebracht op plaatsen die voor ons verstaanbaar zijn. De assemblage is veranderlijk en staat open voor contestatie. Deze kijk op plaatsen staat ons toe te zien hoe activisten aansluiting vinden bij bepaalde ruimtelijke structuren die voortdurend opnieuw geproduceerd kunnen worden. Het is net doorheen assemblage dat de 'agency' van sociale bewegingen tot uiting komt. 'Agency', of de capaciteit tot handelen en veranderen, gaat dus niet enkel uit van specifieke plaatsgebonden mobilisatie, maar eerder van de manier waarop losstaande plaatsen, activisten en discoursen samen gebracht worden in een bepaalde toestand. Het proces is dynamisch, de situatie tijdelijk en veranderlijk. Aan de hand van deze assemblagebenadering analyseert dit artikel het Jordan River Peace Park, een project van 'Friends of the Earth Middle East' (FOEME). Deze milieubeweging brengt mens, natuur en infrastructuur samen in een nieuwe geheel dat hun eigen visie en doel ondersteunt. Door te tonen hoe FOEME de ruimte invulling geeft, wordt duidelijk welke denkpatronen ons de ruimte als een coherent geheel laten zien. De studie tracht deze veronderstellingen net in vraag te stellen en te tonen wat voor 'agency' ze de plaats binnenbrengen. Volgende bevindingen zijn het resultaat van veldwerk in Jordanië (2010) en Israël (2012) waar ik meerdere malen de plaats van het park bezocht en interviews afnam met betrokkenen.

\section{Het Jordan River Peace Park}

De Jordaan stroomt verweesd door het ontoegankelijke grensgebied tussen Jordanië en Israël dat is afgesloten met prikkeldraad en wachtposten. Maar er zijn openingen. In 2006 kondigde FOEME aan het initiatief te nemen in de creatie van een grensoverschrijdend 'vredespark' tussen Israël en Jordanië. De organisatie is zelf actief in zowel Jordanië, Israël als Palestina. Het park zal zich situeren in het noorden van de Jordaanvallei, waar de Jordaan en de Yarmouk samenvloeien. Momenteel is het park nog niet gerealiseerd en zijn de onderhandelingen tussen FOEME en de Jordaanse en Israëlische overheden lopende, maar FOEME-leden gidsen wel al toeristen rond in het gebied. De Jordaanse kant van het park is nog steeds een militair domein. Aan de Israëlische zijde is er een openluchtmuseum, uitgebaat door de leden van de aangrenzende kibboets Gesher, dat de geschiedenis van de eerste Joodse kolonisten in de regio verheerlijkt. Desondanks vindt FOEME deze plaats geschikt om transnationale milieucoöperatie tot stand te brengen. Volgens de organisatie maakt het gedeelde natuurlijke en historische erfgoed samenwerking noodzakelijk. Tegelijkertijd kan ecotoerisme wederzijdse economische voordelen bieden. Op deze manier beoogt FOEME een warme en meer coöperatieve vrede te bereiken tussen de twee landen. Deze assumpties zijn echter geen evidenties die van de plaats zelf uitgaan, ze worden door FOEME geïntroduceerd. Door de plaats doelbewust, stap voor stap, te assembleren, zowel fysiek als narratief opnieuw samen te stellen, krijgen deze aanspraken grip op het Israëlische en Jordaanse deel van het park. Doorheen een discours van ecologische vrede en vooruitgang tracht FOEME alternatieve grenzen te trekken en een nieuwe eenheid naar de plaats te brengen. In FOEME's utopische visie wordt de ruimte een blauwdruk voor een verlichte maatschappij, waarin plaats is voor natuurconservatie en vrede. FOEME stelt de plaats samen door connecties te 


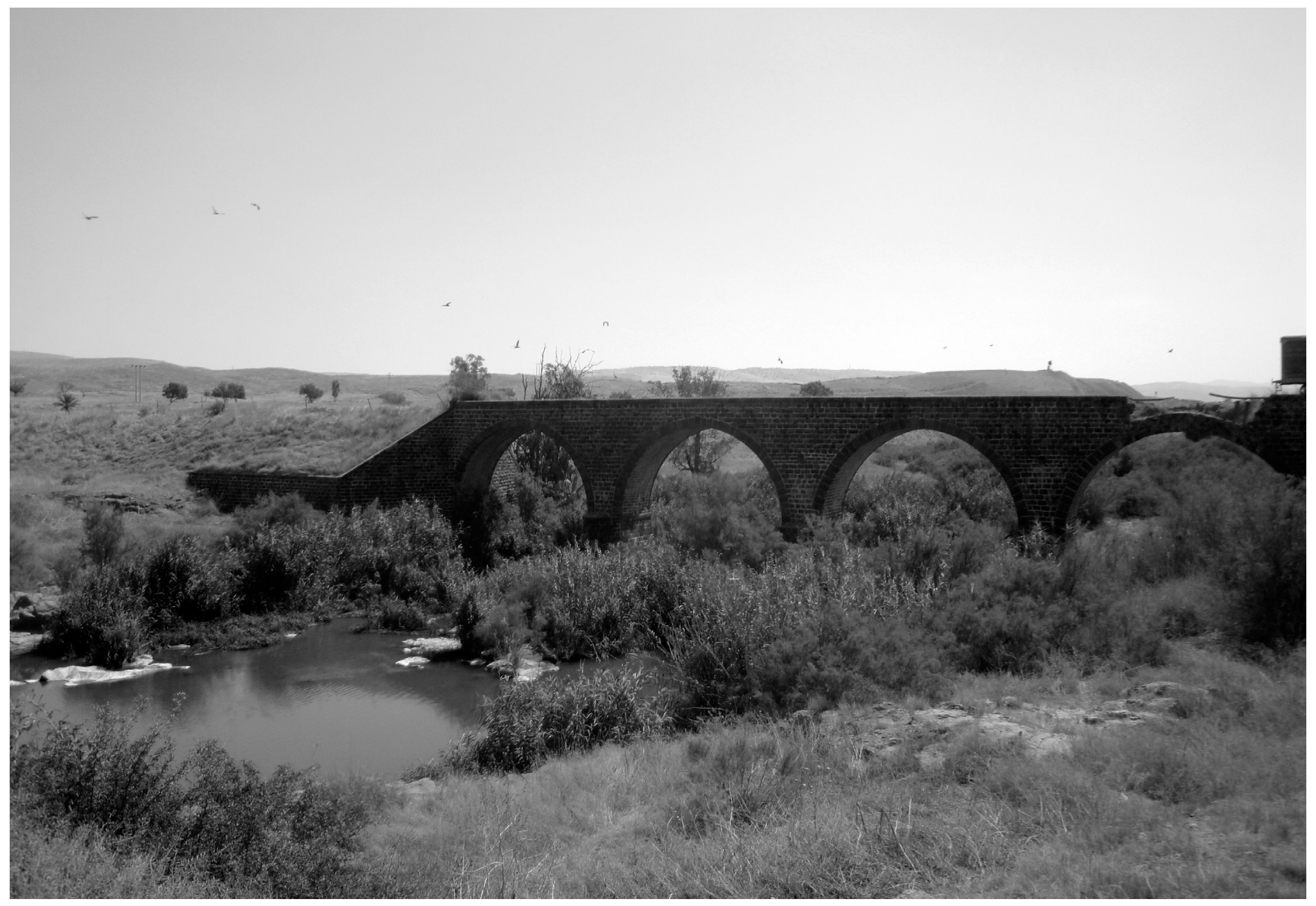

Restanten van de Ottomaanse brug over de Jordaan. Foto: Dorien Vanden Boer

maken tussen bepaalde narratieven, paradigma's en praktijken enerzijds en de natuur, mensen en infrastructuur van het park anderzijds. Vrede wordt zo niet enkel als idee in de plaats geïntroduceerd, het krijgt een tastbare, materiële vorm in het park.

\section{Vrede krijgt een tastbare, materiële vorm in het park}

\section{Constructie van een consumeerbare natuur}

De kaarten van het park die FOEME ontwikkeld heeft, laten gecontesteerde politieke grenzen buiten beschouwing en tonen het water van de Jordaan als een regionale levenslijn. Dit beeld wordt gevoed door een presentatie van natuur zoals die zou kunnen zijn en niet zoals die momenteel is. Terwijl de plaats herdacht wordt als een symbool van vrede en samenwerking, wordt het latente potentieel van de natuur naar voor geschoven. Zo worden parallellen getrokken tussen de onvolmaakte natuur en de gebrekkige vrede tussen Israël en Jordanië. De plannen van het Peace Park tonen in detail hoe technische ingrepen en transnationale samenwerking de gedegradeerde natuur kunnen herstellen. Het opwaarderen van de natuur gaat volgens FOEME niet enkel gepaard met een grotere biodiversiteit, maar ook met economische productiviteit en het genereren van jobs. Een grote aanpassing is het opnieuw laten overstro- men van het reservoir van de voormalige hydro-elektrische centrale. Volgens een Israëlische FOEME-gids kan dit niet enkel natuurherstel, maar ook de toeristische ontwikkeling ten goede komen: "Het meer kan een trekpleister worden voor de 500 miljoen vogels die elk jaar trekken tussen de woestijn en de zee. Dan kunnen Israëli's en Jordaniërs baat hebben bij het toerisme hier, het zou iets goed zijn voor beide kanten, iets dat gemeenschappelijk is". Water, vogels, toeristen en de lokale bevolking worden dus onder een bepaalde constellatie gebracht die FOEME's ideaal van vrede, duurzame conservatie en ecotoerisme belichaamt. Deze assemblage maakt het tevens mogelijk dat de plaats een als een te consumeren goed op de toeristische markt geïntroduceerd wordt. De sociale relaties die gevormd worden zijn normaliserend, genereren in- en uitsluiting en bepalen mee wat voor 'agency' de plaats genereert.

\section{Een vredesinfrastructuur}

De infrastructuur die aanwezig is in het park heeft een controversiële geschiedenis, die zich vooral situeert tijdens de Joodse kolonisatie tijdens de Britse Mandaatperiode in Palestina en het Israëlisch-Arabische conflict dat volgde na de onafhankelijkheid van Israël. Een hydro-elektrische krachtcentrale met kanalen, een treinstation en de arbeidershuizen van 'Tel Or' (Hebreeuws voor berg van licht) werden rond 1930 door de Zionistische Palestine Electric Corporation gebouwd op de oostelijke Jordaanoever, op wat nu Jordaans grondgebied is. Het museum 'Old Gesher' aan de Israëlische kant van het park getuigt van het belang dat 
deze plek nog steeds heeft voor Israëli's. Niet enkel omdat dit de enige Joodse nederzetting was ten oosten van de Jordaan maar ook omdat de elektriciteitscentrale een symbool is voor de moderniteit en ontwikkeling die Joodse kolonisten volgens het museum naar deze uithoek van Palestina brachten. FOEME is zich zeer goed bewust van de gevoeligheden die de overblijfselen van deze gebouwen met zich meebrengen en gaat hier pragmatisch mee om. Een Jordaans FOEME-medewerker verduidelijkte: "Het is een van de eerste Joodse nederzettingen in de regio, dus ze [Israëli's] hebben een sterke connectie met deze plaats. Nu, wanneer we hier ecotoerisme proberen op te leggen, is het gemakkelijker voor mensen om het park te bezoeken en zich niet te concentreren op de geschiedenis van Joodse Israëli's in de regio". Hieruit blijkt duidelijk dat FOEME de infrastructuur in het park articuleert op een gedepolitiseerde wijze, door de nadruk te leggen op ecotoerisme. De arbeidershuizen worden ecologische logementen voor vogelliefhebbers, het treinstation wordt omgevormd tot een verhuurplaats van fietsen en de turbinehal van de elektriciteitscentrale wordt herschapen tot bezoekerscentrum. De waterkrachtcentrale zal bovendien beschouwd worden als gemeenschappelijke regionale verwezenlijking van Joden en Arabieren. Zo wordt het park een plaats van ontmoeting. Dit discours van historische samenwerking dient als springplank ter bevordering van hedendaagse economische en ecologische coöperatie, waar FOEME naar streeft. Het verhaal wordt verder bevestigd in de manier waarop FOEME zich uitspreekt over drie bruggen in het Peace Park. De ruïnes van de Romeinse, Ottomaanse en Britse bruggen die de Jordaan oversteken, symboliseren voor FOEME een vergeten openheid en herinneren aan een tijd waarin gelijkgezinden elkaar nog konden ontmoeten in wat nu een gesloten militaire zone is. Het Jordan River Peace Park tracht deze verloren connectiviteit en openheid denkbaar en reëel te maken.

\section{Adapteren wie niet past?}

Net als de natuur en infrastructuur wordt menselijke aanwezigheid in het toekomstige park geïntegreerd op een manier dat het een coherent geheel vormt in het licht van FOEME's visie. Hieruit blijkt dat mensen sterk bijdragen aan de manier waarop de plaats herkenbaar is en wat voor 'agency' er uitgaat van de plaats. Dit heeft andere gevolgen voor de verschillende categorieën mensen die momenteel aanwezig zijn in de plaats. FOEME maakt de aanwezigheid van de Jordaanse militairen aanvaardbaar voor toeristen door hen tot parkwachters om te vormen. Jordaanse landbouwers bewerken momenteel de droge bedding van het reservoir. Hun waterintensieve landbouw is volgens de FOEME-staf echter niet compatibel met het natuurherstel dat de organisatie beoogt. Uit de interviews was niet duidelijk of en hoe de boeren in het park geïntegreerd zouden worden. Het enige dat de FOEME-staf hierover kwijt wilde, is dat de lokale landbouwers aanzienlijk grotere voordelen zouden hebben bij het toerisme in vergelijking met de opbrengst van hun velden. Deze rationale werd bevestigd door de burgemeester van het aangrenzende Muaz Bin Jabal, betrokken in het Peace park project. Naast Jordaanse boeren, bewerken ook Israëlische boeren land aan de Jordaanse zijde van het toekomstige park. Deze regeling is een restant van het Joodse landeigenaarschap in Jordanië dat werd toegekend naar aanleiding van de bouw van de waterkrachtcentrale. Dankzij een clausule in het vredesverdrag tussen Jordanië en Israël steken Israëli's elke dag de grens over om deze velden te bewerken in wat nu een Jordaans militair domein is. Deze overeenkomst is voor FOEME een aanknopingspunt en voorbeeld voor ecologische vredesopbouw. Bovendien benadrukte FOEME dat deze boeren reeds over de nodige knowhow en technologie beschikken en op een duurzame en waterzuinige manier (druppelirrigatie) aan landbouw doen, die compatibel is met de milieuconservatie in het park. Op die manier kunnen de Israëlische boeren wel in het park geassembleerd worden. De Jordaanse omwonenden daarentegen werden in eerder stereotype, traditionele functies geplaatst. Zo ziet FOEME economische opportuniteiten in het park voor de lokale Jordaniërs in het verkopen van artisanale producten en traditionele gerechten of het vertellen van verhalen. Voor het Palestijnse verhaal is er bovendien volledig geen plaats. Het relaas van het vernielde Palestijnse dorp Jisr-el Majame komt niet aan bod in het park. Het dorp werd overbouwd door de huidige kibboets 'Gesher'. En hoewel de Palestijnse tak van FOEME initieel bij de planning van het park betrokken was, is dit momenteel niet meer het geval. FOEME-stafleden (Jordaans, Israëlisch en Palestijns) bemerkten dat dit te wijten was aan het feit dat de Palestijnen niet aan het park grenzen. De exclusieve focus op de territorialiteit van het park, sluit Palestijnen uit als partner. Wederom toont dit aan hoe FOEME's specifieke assemblage de plaats een 'agency' genereert die inclusie en exclusie normaliseert en sociale relaties vorm geeft.

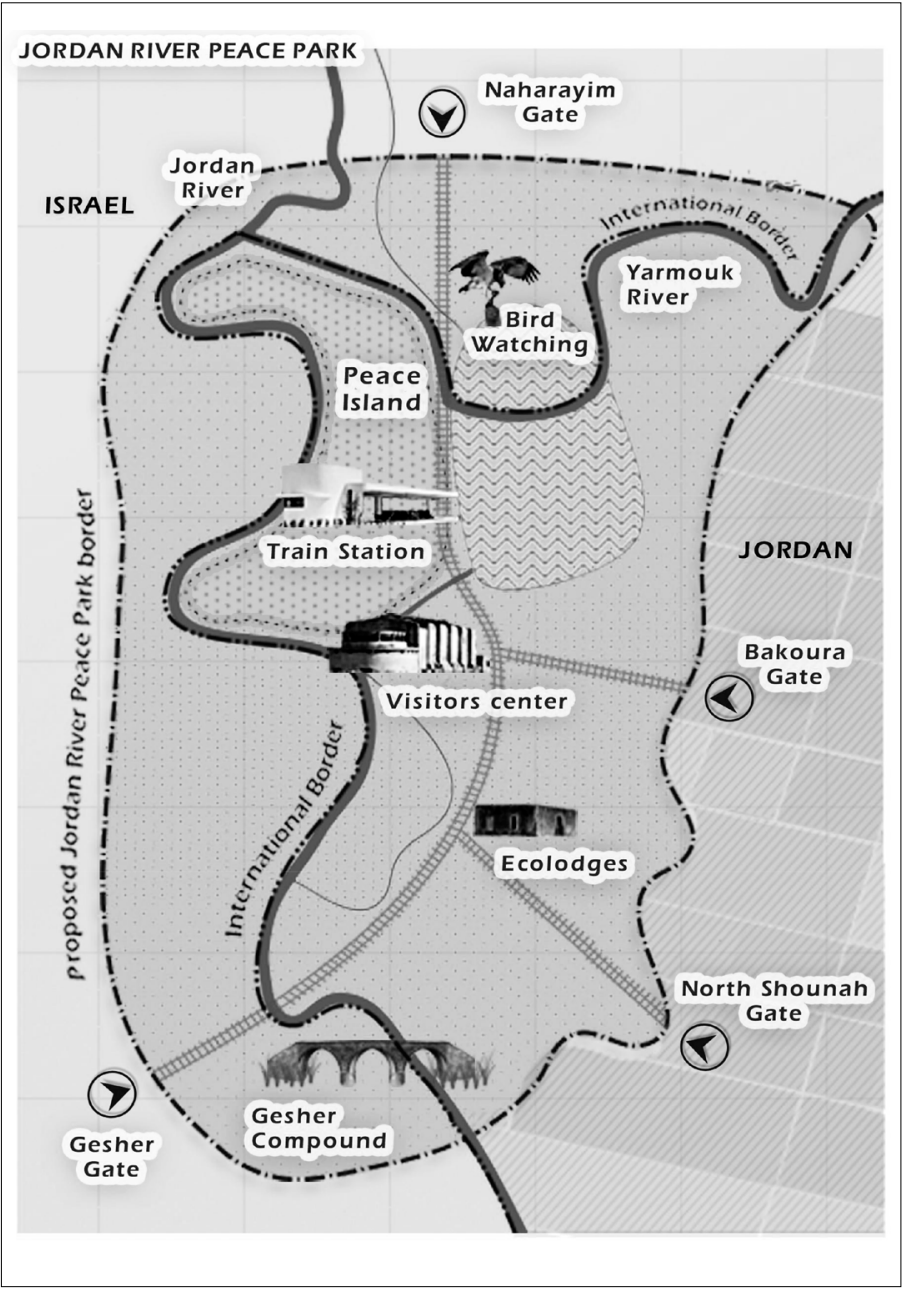

Kaart van FOEME's visie van het toekomstige Jordan River Peace Park Bron: Friends of the Earth Middle East, http://foeme.org/uploads/ website_interactive_map.pdf 


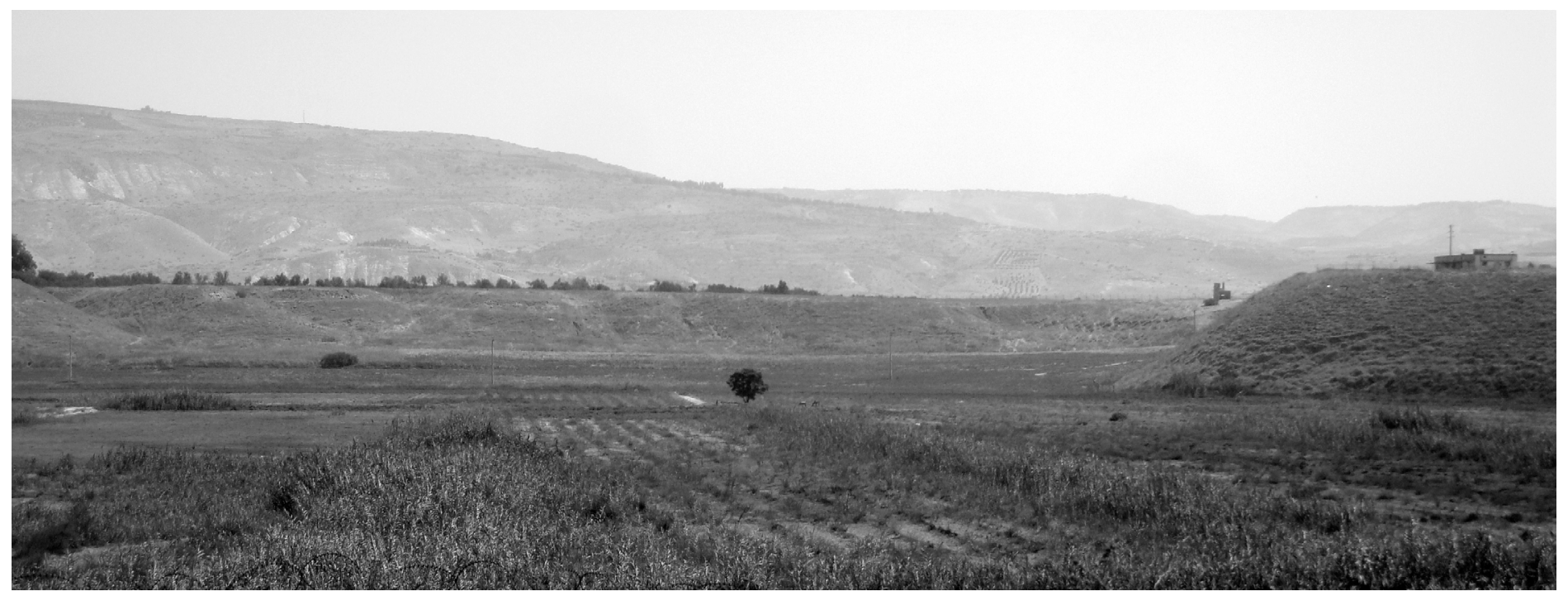

Velden van de Jordaanse boeren in de bedding van het voormalige reservoir van de waterkrachtcentrale. Foto: Dorien Vanden Boer

\section{Insluiten van toeristen}

Een groep mensen die expliciet in het park worden geloodst, zijn toeristen. Samen met hen sluipen specifieke verwachtingen, voorwaarden en paradigma's de plaats binnen. Zo worden er in de plannen van het Peace Park activiteiten, eetgelegenheden en logement voorzien, die de toestroom van gedistingeerde toeristische niches zoals vogelliefhebbers moeten faciliteren. Hun aanwezigheid staat garant voor de conservatie van de natuur, die door toerisme op een alternatieve manier productief gemaakt wordt. Het integreren van nationale en internationale toeristen in de assemblage van het Peace Park is dus niet enkel vitaal voor de economische rendabiliteit van het park maar kan volgens FOEME een belangrijk educatief effect hebben op de lokale bevolking. Of zoals een van de Jordaanse stafleden stelde: "Wanneer de lokale gemeenschappen zien dat mensen van buitenaf naar het park komen, zullen ze zich realiseren dat het [de natuur] iets belangrijk is". Voor FOEME is het Peace Park meer dan een toeristische attractie. Het park zelf is een instrument om het ecologische bewustzijn binnen de maatschappij aan te scherpen. Een van de Jordaanse FOEME stafleden vertelde dat "we moeten evolueren naar een verlichte maatschappij". Hij voegde hieraan toe dat dit enkel mogelijk was door middel van onderricht dat de lokale bevolking kan laten zien hoe belangrijk de natuur is voor hun welzijn. Met het park als baken, hoopt FOEME ecologische kennis te verspreiden in de regio en mensen meer milieubewust te maken.

\section{Een neoliberale rationale schemert doorheen FOEME's plannen}

\section{Een neoliberale 'agency'?}

FOEME geeft invulling aan de ruimte door natuur, infrastructuur en mensen samen te brengen in een bepaalde constellatie waarbij bepaalde discoursen, paradigma's en denkbeelden al dan niet intentioneel het park binnen geloodst worden.
Deze manieren om naar de wereld te kijken ondersteunen FOEME's aanspraken en genereren herkenbaarheid voor de lokale bevolking, bezoekers, politici en activisten. Maar deze herkenbaarheid is niet neutraal en de waarheden die de plaats vorm geven hebben hun eigen verdoken agenda.

Een neoliberale rationale schemert doorheen FOEME's plannen: de conservatie van natuur door vermarkting, het openen van de plaats voor de toeristische markt, de visie op moderniteit, de noodzaak van ontwikkeling en de lokale gemeenschappen die steevast als traditioneel bestempeld worden en vervolgens uitgesloten of onder specifieke voorwaarden in het park gedoogd worden. Deze assumpties sluipen de assemblage binnen en geven mee vorm aan FOEME's project als omstandigheden waarover FOEME geen volledige controle heeft. Op die manier medieert FOEME niet enkel de eigen visie in de plaats maar ook een neoliberale rationaliteit die een waarlijk politiek project depolitiseert en homogeniseert ten koste van het emancipatorische potentieel en de multipliciteit van de ruimte.

Dorien Vanden Boer (dorien.vandenboer@ugent.be) is doctoraatstudent bij de Middle East and North Africa Research Group aan de Universiteit Gent. Haar onderzoek richt zich op de politiek van toerisme en ruimtelijkheid in de context van het Israëlisch-Palestijns conflict.

\section{Literatuurselectie}

Ecotech Jordan (2008) The Jordan River Peace Park Pre-Feasibility Study.

Duffy, R. (2007) Peace parks and global politics: the paradoxes and challenges of global governance. In: A. Saleem (Ed.), Peace Parks: Conservation and Conflict Resolution. Massachusetts: the MIT Press.

Massey, D. (2005) For Space. London: Sage.

McFarlane, C. (2009) Translocal assemblages: Space Power and

Social Movements. Geoforum 40 (4): 561-567.

Nicholls, W., Miller, B. \& Beaumont, J. (2013) Spaces of Contention.

Spatialities and Social Movements. Farnham: Ashgate. 